\title{
Low-Temperature FTIR Spectroscopic and Theoretical Study on an Energetic Nitroimine: Dinitroammeline (DNAM)
}

\author{
P. N. Simões, ${ }^{*}, \dagger$ I. Reva,,${ }^{\dagger}$ L. M. Pedroso, ${ }^{\dagger}$ R. Fausto,, and A. A. Portugal $^{\dagger}$ \\ Department of Chemical Engineering, University of Coimbra, P-3030-790 Coimbra, Portugal, and \\ Department of Chemistry, University of Coimbra, P-3004-535 Coimbra, Portugal
}

Received: November 24, 2007; In Final Form: January 29, 2008

\begin{abstract}
This paper presents an overview of recent progress in spectroscopic studies of the energetic nitroimine 4,6bis(nitroimino)-1,3,5-triazinan-2-one (DNAM), based on experimental and theoretical data. The following topics are considered: variable temperature FTIR spectroscopy $\left(4000-400 \mathrm{~cm}^{-1}\right)$ applied to the study of natural and isotopically substituted (deuterated) samples aiming to obtain a successful vibrational assignment of the spectra and to investigate H-bonding interactions; extensive theoretical work based on accurate quantum chemical calculations (ab initio MP2 and DFT/B3LYP; harmonic and anharmonic vibrational calculations) to model and help interpreting the experimental findings, as well as to provide fundamental data on this simple prototype nitroimine that can be used as a starting point to the study of more complex related compounds. This work allowed us to reveal detailed features of the IR spectrum of the title compound, presenting, for the first time, plausible assignments.
\end{abstract}

\section{Introduction}

Nitramino-1,3,5-triazines are a subclass of nitramines $(\mathrm{N}$ nitroamines), which are among the most important categories of energetic molecules. ${ }^{1,2}$ A compound originally named as (di)nitroammeline (DNAM) was reported for the first time about five decades ago by Atkinson. ${ }^{3}$ The nitrated product, which could not be fully characterized at that time, was supposed to be a primary nitramine specimen (primary and secondary nitramines are compounds having the structures $\mathrm{RHN}-\mathrm{NO}_{2}$ and $\mathrm{R}^{1} \mathrm{R}^{2} \mathrm{~N}-\mathrm{NO}_{2}$, respectively). Primary nitramines have the tendency to a prototropic (nitro)amine-(nitro)imine tautomerism ${ }^{4}$ $(N$-nitroimines, also called nitrimines, are compounds having the structure $\mathrm{R}^{1} \mathrm{R}^{2} \mathrm{~N}=\mathrm{N}-\mathrm{NO}_{2}$ ), depending on the particular structure of the substituent.

After evaluating DNAM as a potential component for composite propellant formulations, ${ }^{5-7}$ we recently resumed the study of the compound from the viewpoint of the fundamental chemistry of nitramines/nitroimines and related issues. ${ }^{8}$ That allowed the scrutiny of the most probable molecular structure of DNAM among a large variety of possible tautomeric forms. As obtained from the X-ray crystallographic analysis of the compound, the prevailing tautomer in crystalline DNAM is that represented in Figure 1a. After the structural characterization, we moved to the spectroscopic investigation of DNAM while continuing to pursue a detailed knowledge on its chemistry and, hopefully, of related compounds.

The study of the vibrational spectra of monomeric DNAM poses some difficulties. The investigation of the infrared spectrum of the monomeric compound has been recently attempted in our laboratory by using the matrix isolation technique. This was, however, unsuccessful due to the decomposition of the compound instead of its sublimation on heating. Moreover, DNAM exhibits quite high chemical reactivity, in

* Corresponding author. Tel: +351 239798 732. E-mail: pnsim@eq.uc.pt.

$\dagger$ Department of Chemical Engineering.

$\doteqdot$ Department of Chemistry. particular in solution, which is why experimental studies of DNAM solutions are extremely difficult. On the other hand, the IR study of DNAM in its neat condensed state can also be considered as a challenge for several reasons.

First, it is recognized that H-bonding is of great importance in many chemical systems, and this is certainly true in the case of crystalline DNAM, in which its occurrence was proven in our previous work ${ }^{8}$ (see Figure 1b). Occurrence of extensive H-bonding represents always a source of complexity in the vibrational analysis of a chemical system. On the other hand, the possibility of occurrence of nitramine-nitroimine tautomerism in DNAM upon changing the experimental conditions can also complicate the vibrational study of the compound. There are some reported works on compounds where nitraminenitroimine tautomerism is virtually possible, such as nitrated derivatives of guanidine ${ }^{9-19}$ and pyridine,${ }^{20-27}$ some nitrated heterocycles, ${ }^{28-34}$ and phenylnitramines. ${ }^{35}$ Nevertheless, there were no previously reported relevant experimental and computational data that could provide much help to the spectroscopic characterization of DNAM.

In the theoretical handling of less studied molecular systems, the choice of the model chemistry is decisive. ${ }^{36}$ In fact, our experience revealed DNAM as a compound whose peculiarities demand reliable quantum chemical methods for its theoretical study. Regarding spectroscopic data, it is well-known that systematic errors in calculated frequencies can arise because of neglecting anharmonic effects, electronic correlation and basis set deficiencies. To get some insight into these factors, and aiming at a reliable description of the experimental frequencies, a comprehensive theoretical work has been performed, including calculations beyond the harmonic approximation. Different methods were used, all of them emphasizing the vibrational properties, aiming at reliable assignments of the experimental IR spectra of DNAM, and to make new data available that, hopefully, can be of help in future studies on related compounds.

In this contribution, we also endeavor to clarify several spectroscopic issues concerning the FTIR spectra (4000-400 


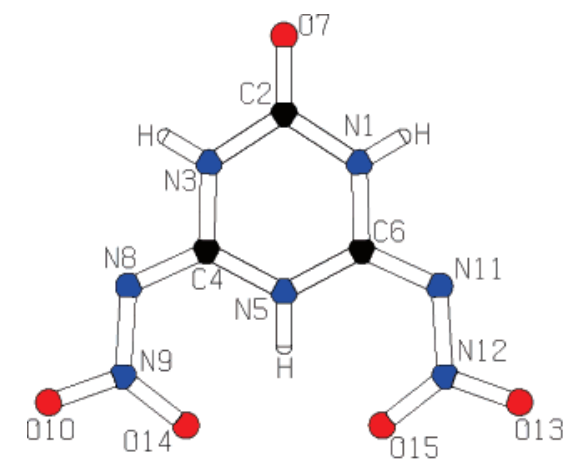

(a)

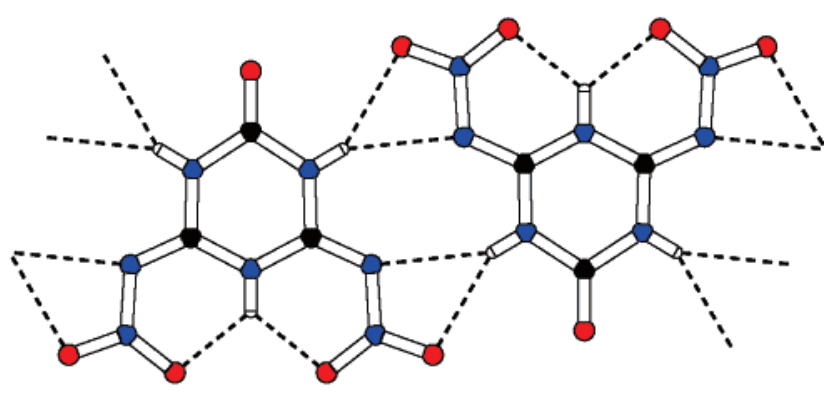

(b)

Figure 1. (a) Atom numbering of the title compound. (b) Diagram showing the chain formation via hydrogen bonds as revealed by X-ray studies. ${ }^{8}$

$\mathrm{cm}^{-1}$ ) of both hydrogenated (DNAM-h) and deuterated DNAM (DNAM-d). For that, the isotopic doping method was combined with spectroscopy in the wide temperature range $(10-300 \mathrm{~K})$. This approach has been demonstrated to be crucial for the successful investigation of $\mathrm{H}$-bonding interactions in condensed media by vibrational spectroscopy methods. ${ }^{37-43}$

\section{Methods}

2.1. Experiment. DNAM was synthesized and purified according to the established methods. ${ }^{3}$ Deuterated samples of DNAM were prepared in two ways to obtain different isotopic concentrations. An amount of ca. $0.5 \mathrm{~g}$ of DNAM was dissolved in a previously prepared solution of $1 \mathrm{~g}$ of $\mathrm{NaHCO}_{3}$ in $10 \mathrm{~mL}$ of $\mathrm{D}_{2} \mathrm{O}$ (Sigma-Aldrich). The solution was filtered and the filtrate was cooled to $0{ }^{\circ} \mathrm{C}$ and then acidified, under stirring, with a solution obtained by dilution of $5 \mathrm{~mL}$ of $\mathrm{DCl}(35 \%$; Sigma-Aldrich) in $5 \mathrm{~mL}$ of $\mathrm{D}_{2} \mathrm{O}$. On the other hand, an amount of ca. $0.533 \mathrm{~g}$ of DNAM was dissolved in a previously prepared solution of $1.1 \mathrm{~g}$ of $\mathrm{NaHCO}_{3}$ in $11 \mathrm{~mL}$ of $\mathrm{H}_{2} \mathrm{O}$. The solution was filtered and the filtrate was cooled to $0{ }^{\circ} \mathrm{C}$ and then acidified, under stirring, with a solution of $\mathrm{DCl}$ ca. $6 \mathrm{~mol} \mathrm{~L}^{-1}$. These procedures allowed the preparation of crystalline deuterated samples with deuterium concentrations of ca. $70 \%$ and $10 \%$, respectively.

The IR spectra $\left(4000-400 \mathrm{~cm}^{-1}\right)$ of polycrystalline native and deuterated DNAM in a $\operatorname{KBr}(1: 200)$ disk, attached to the cold finger of an APD Cryogenics closed-cycle helium refrigeration system with a DE-202A expander, were recorded with a Mattson Infinity 60AR series FTIR spectrometer, with spectral resolution $1 \mathrm{~cm}^{-1}$. The temperature $(10-300 \mathrm{~K})$ was measured directly at the sample holder by a silicon diode temperature sensor, connected to a digital controller (Scientific Instruments, model 9650-1), with accuracy $0.1 \mathrm{~K}$. The sample temperature during registration of spectra was kept stable within $0.2 \mathrm{~K}$. The temperature-induced spectral changes observed for all samples were found to be reversible and highly reproducible.

2.2. Computational Details. As mentioned before, the reported experimental and computational spectroscopic data on primary nitramines or their nitroimine counterparts are rather scarce, which precludes the assignment of the DNAM spectra to be made by comparison with literature data. In addition, it is known that the description of modes originated in the $\mathrm{NH}$ fragment is not obvious in many cases, either due to the influence of anharmonicity or because of inadequacies of the theoretical approach. ${ }^{44-46}$ To overcome these difficulties in interpreting the present experimental findings, in this study DNAM was extensively studied theoretically.

All calculations here reported were performed with the Gaussian03 package. ${ }^{47}$ Quantum chemical methods based on density functional theory (DFT) $)^{48,49}$ as well as ab initio MøllerPlesset second-order perturbation theory (MP2) ${ }^{50}$ methods were used. Due to the considerable computational resources and time demanded by the latter, a direct comparison of DFT and ab initio (MP2) methods was made possible only for the Popletype basis sets from $6-31 \mathrm{G}(\mathrm{d}, \mathrm{p})$ up to $6-311++\mathrm{G}(\mathrm{d}, \mathrm{p})$. Nevertheless, calculations within the framework of DFT methods have been performed throughout by applying a wider basis sets range. The DFT computations were accomplished using the Beckestyle 3-parameter with the Lee-Yang-Parr correlation functional (B3LYP). ${ }^{51-53} \mathrm{~A}$ total of 16 Pople-type basis sets, ${ }^{54-58}$ from $6-31 \mathrm{G}(\mathrm{d}, \mathrm{p})$ to $6-311++\mathrm{G}(3 \mathrm{df}, 3 \mathrm{dp})$, was used. The augcc-pVQZ Dunning correlation-consistent basis set ${ }^{59}$ was also employed for checking the effects of basis set truncation on spectral parameters. This sort of calculations was performed for the monomer in vacuum.

When looking for an appropriate band to be assigned to a calculated vibrational mode (or vice versa), one should be aware that the observed frequencies are perturbed by a crystalline force field, whereas the calculations that have been made are related to the isolated molecule. This is even more crucial when dealing with H-bonding. Because DNAM is a typical hydrogen-bonded system, involving both intra- and intermolecular $\mathrm{H}$-bonds in the crystal, this issue has also been addressed theoretically in great detail in the present work. The main goal was to obtain original theoretical spectroscopic data and, concomitantly, to propose plausible assignments for the experimentally obtained IR spectra. We have used three different strategies to tackle this problem: (i) simulations for monomeric DNAM in liquid phase using the polarized continuum model (PCM) model; ${ }^{60-65}$ (ii) in vacuum computations by means of supermolecular models with up to three DNAM molecules (Figure 2); (iii) in vacuum anharmonic frequency calculations using a second-order perturbative treatment ${ }^{66,67}$ on DNAM alone and DNAM-water complex (Figure 3 ), in the latter case to model in a simplified way the intermolecular H-bonds.

For each method/level of theory mentioned above, the molecular geometries were fully optimized by the force gradient method using the Berny algorithm ${ }^{68}$ and applying the tight convergence criteria ${ }^{47}$ In all cases, the nature of the stationary points (minima) was confirmed by vibrational frequency calculations.

\section{Results and Discussion}

3.1. Vibrational Spectrum of DNAM. From 18 atoms in DNAM, $3 \times 18-6=48$ vibrational modes are expected for a single molecule. From the X-ray data it is known that crystals of DNAM are orthorhombic with space group $P 2{ }_{1} 2_{1} 2_{1}$, and $Z$ $=4 .{ }^{8}$ Consequently, one may expect the 48 normal modes to 


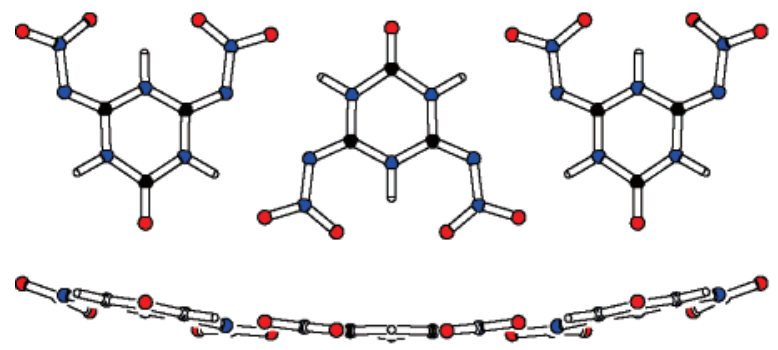

(a) From modeling [B3LYP/6-311+G(d,p)].

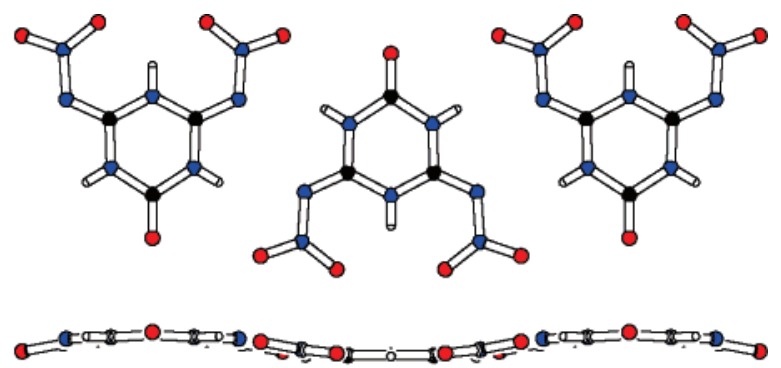

(b) From X-ray data.

Figure 2. Comparative views of (a) optimized geometry of supermolecular model based on a trimer of DNAM and (b) experimentally resolved structure of chain from X-ray data.

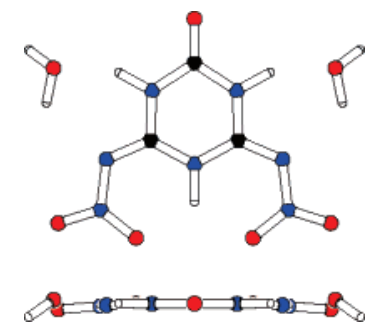

Figure 3. Different views of a DNAM-water complex model used in the anharmonic vibrational calculations.

be quadrupled in the crystals as a result of coupling between the motions of the four molecules in the unit cell. In addition, there are 12 external modes resulting from molecular librations and another 12 from translations, three of which are acoustic. Thus, excluding any isotopic effect, a total of 213 modes is possible, although not all would be observable, given that some are only weakly IR active and/or they overlap with stronger peaks.

In this section we advance with tentative general assignments mainly based on the group frequency concept and on the comparison with (few) reported measurements on compounds with some affinities with DNAM. Whenever considered relevant, brief references will be made to the results of the theoretical calculations, which will be further discussed and detailed in section 3.2. In what follows, DNAM-h holds for hydrogenated crystalline DNAM, and DNAM-d for its isotopically labeled (deuterated) counterpart. Unless otherwise stated, the peak frequencies referred below correspond to spectra collected at the lowest temperature (see Figures 4-6).

3.1.1. Spectral Range $3400-2000 \mathrm{~cm}^{-1}$. Figure 4 details the spectra of DNAM-h in $\mathrm{KBr}$ in the $3400-2000 \mathrm{~cm}^{-1}$ region and at temperatures ranging from 300 to $10 \mathrm{~K}$. The spectra of DNAM-d, with ca. $10 \%$ and $70 \%$ of the doping isotope (traces $\mathrm{A}$ and $\mathrm{B}$, respectively), at $10 \mathrm{~K}$, are also included in this figure.

The spectrum of DNAM-h clearly shows two broad bands at 3224 and $3087 \mathrm{~cm}^{-1}$. A shoulder at $3247 \mathrm{~cm}^{-1}$ becomes observable only after cooling to $10 \mathrm{~K}$. The peak frequencies of these bands are red-shifted upon cooling by $7 \mathrm{~cm}^{-1}\left(3087 \mathrm{~cm}^{-1}\right.$ band) or less. The expected narrowing effect due to the temperature lowering is not very pronounced, which may be an indication of the considerable structural rigidity of the H-bond network in DNAM. The intensity of these bands is considerably lowered on going from hydrogenated to deuterated DNAM, whose counterparts are visible as new bands appearing at 2423 (shoulder), 2399 and $2337 \mathrm{~cm}^{-1}$ with isotopic frequency ratios of $3247 / 2423=1.340,3224 / 2399=1.344$, and $3087 / 2337=$ 1.321 , respectively. The temperature dependence of the deuterated samples is essentially identical to that described for hydrogenated DNAM. The bands in this high-frequency range of the spectrum are indubitably ascribable to the NH (or ND) stretching vibrations of DNAM-h (or DNAM-d). Furthermore, the strong similarity between the NH and ND stretching band profiles, as well as the above-mentioned isotopic ratios, clearly indicates the protonic nature of these bands.

3.1.2. Spectral Range $2000-1000 \mathrm{~cm}^{-1}$. The spectra of DNAM-h and DNAM-d in $\mathrm{KBr}$ within the $2000-1000 \mathrm{~cm}^{-1}$ range are shown in Figure 5.

The intense band at $1771 \mathrm{~cm}^{-1}$ is unequivocally due to the stretching vibrational mode of the carbonyl moiety, $v(\mathrm{CO})$. The peak frequency is essentially invariant with temperature, being not affected by deuteration. The lowest intensity peak at 1800 $\mathrm{cm}^{-1}$, which almost vanishes in the highly deuterated sample, and the peak at $1741 \mathrm{~cm}^{-1}$, which is not affected by temperature changing and becomes more prominent upon deuteration, are here tentatively assigned to a cooperative vibration of the carbonyl groups within the chains in which DNAM molecules are organized (see section 3.2.3 below).

For DNAM-h, the spectral region $1650-1500 \mathrm{~cm}^{-1}$ comprises two main bands, centered at 1615 and $1533 \mathrm{~cm}^{-1}$. The first (at $1615 \mathrm{~cm}^{-1}$ ) does not exhibit any noticeable change in profile and peak frequency upon temperature variation and deuteration. This behavior suggests that the former band should not be a proton related band (it is also unlikely to expect at such high vibrational frequencies absorptions due to the $\mathrm{NH}$ in-plane modes). A band at $1614 \mathrm{~cm}^{-1}$ has been recently reported $^{32}$ for the IR spectrum of nitroimine 3,5-diamino-1nitroamidino-1,2,4-triazole, a compound with some local similarities with DNAM, although the band has not been ascribed. The IR spectrum of 2-nitroimino-5-nitrohexahydro-1,3,5-triazine in $\mathrm{KBr}$ has also been reported, ${ }^{33}$ showing a band at $1615 \mathrm{~cm}^{-1}$ that was attributed to a $v(\mathrm{C}=\mathrm{N})$ mode. We then assign the peak at $1615 \mathrm{~cm}^{-1}$ to a $v(\mathrm{C}=\mathrm{N})$ stretching mode. This assignment is also supported by strong evidence from theoretical calculations (DNAM-h versus DNAM-d spectra). The calculated anharmonic frequencies from the DNAM-water complex model (Figure 3) led to the $1638 \mathrm{~cm}^{-1}$ and $1618 \mathrm{~cm}^{-1}$ values for vibrational modes involving mainly the $\mathrm{C}=\mathrm{N}$ coordinate (see Table 2 below).

The band at $1533 \mathrm{~cm}^{-1}$ is with all probability due to the nitro group antisymmetric stretching mode, $v_{\text {as }}\left(\mathrm{NO}_{2}\right)$. As seen from Figure 5, this band is quite insensitive to temperature but its profile is somewhat influenced by isotopic exchange. Literature values that allow a straightforward comparison with our results are scarce. Astakhov and co-workers ${ }^{32}$ reported for 3,5-diamino1-nitroamidino-1,2,4-triazole the $v_{\text {as }}\left(\mathrm{NO}_{2}\right)$ vibrational mode as giving rise to a band at $1431 \mathrm{~cm}^{-1}$ (although the bands at 1564 and $1517 \mathrm{~cm}^{-1}$ were also reported). On the other hand, the bands at 1605 and $1570 \mathrm{~cm}^{-1}$ were attributed to vibrations of nitro group in 2-nitroimino-5-nitrohexahydro-1,3,5-triazine by Cliff et al. ${ }^{33}$ 


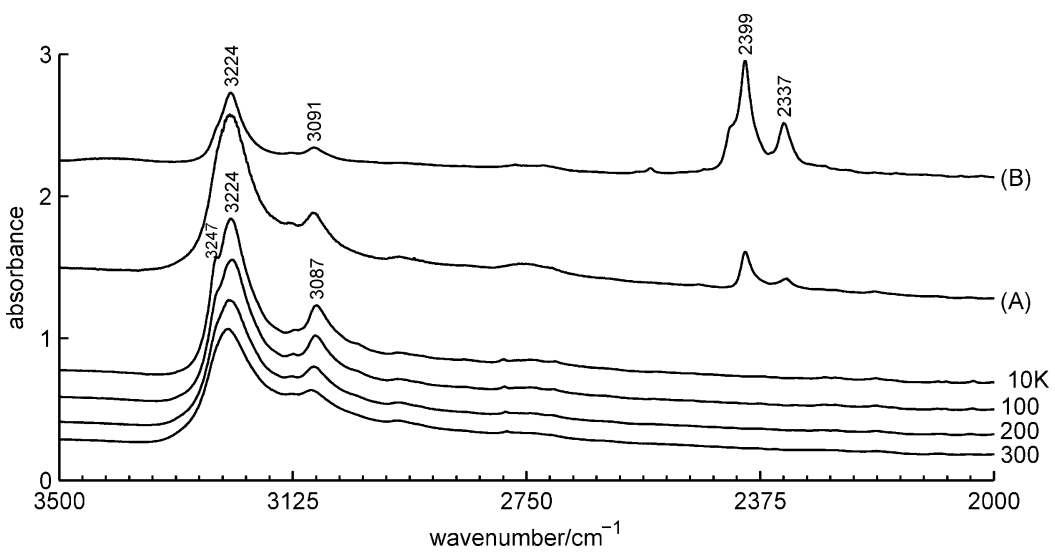

Figure 4. FTIR spectra (range $3400-2000 \mathrm{~cm}^{-1}$ ) of DNAM-h at the indicated temperatures and of DNAM-d (with $10 \%$ (A) and $70 \%$ (B) deuterium content) at $10 \mathrm{~K}$.

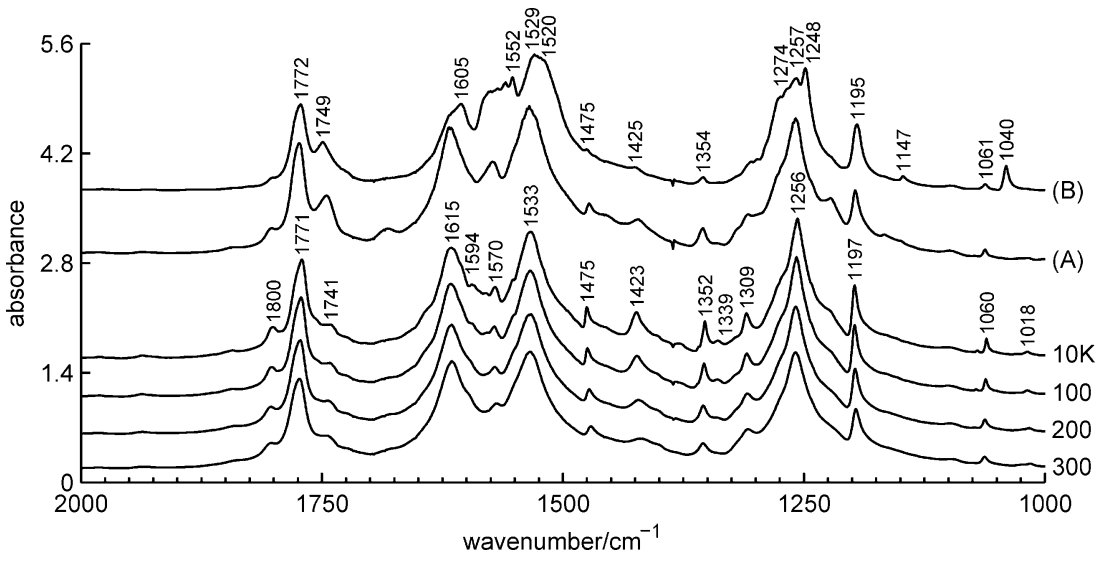

Figure 5. FTIR spectra (range 2000-1000 $\mathrm{cm}^{-1}$ ) of DNAM-h at the indicated temperatures and of DNAM-d (with 10\% (A) and $70 \%$ (B) deuterium content) at $10 \mathrm{~K}$.

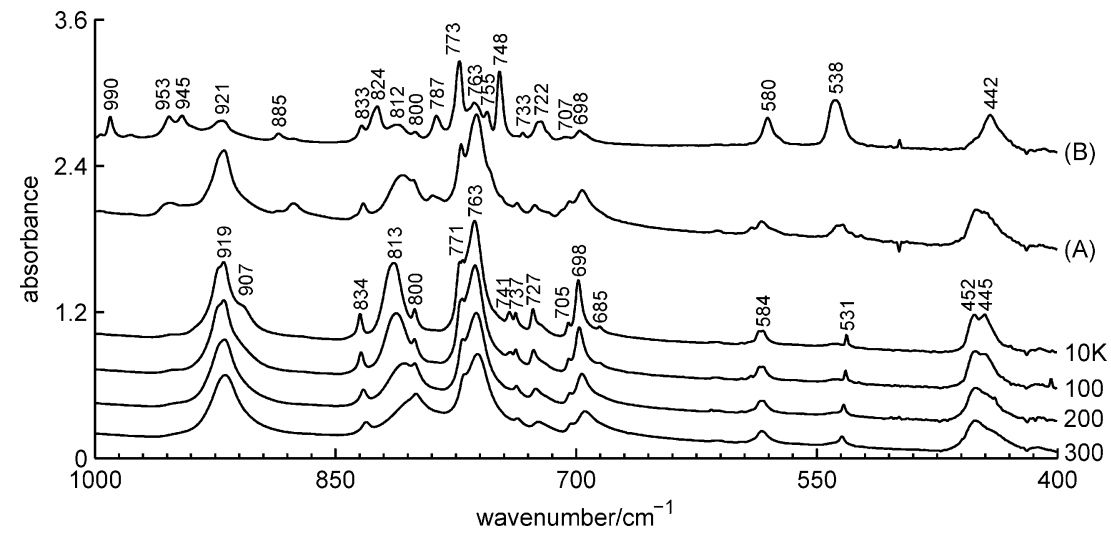

Figure 6. FTIR spectra (range 1000-400 $\mathrm{cm}^{-1}$ ) of DNAM-h at the indicated temperatures and of DNAM-d (with $10 \%$ (A) and $70 \%$ (B) deuterium content) at $10 \mathrm{~K}$.

It is interesting to notice that in the spectrum of the highly deuterated sample (see trace B of Figure 5) at least three new intense bands are observed at 1605 , ca. 1552 and $1520 \mathrm{~cm}^{-1}$ (this latter strongly overlapping the band at $1529 \mathrm{~cm}^{-1}$ ). These bands are also probably due to the $v(\mathrm{C}=\mathrm{N})(1605$ and, probably, $\left.1552 \mathrm{~cm}^{-1}\right)$ and $v_{\mathrm{as}}\left(\mathrm{NO}_{2}\right)\left(1520 \mathrm{~cm}^{-1}\right)$ modes: a possible explanation for the observation of these bands is that the $v(\mathrm{C}=\mathrm{N})$ and $v_{\text {as }}\left(\mathrm{NO}_{2}\right)$ modes in the deuterated sample can couple more with the ND coordinate than with $\mathrm{NH}$ in the case of the light isotopologue (because the deuterium is heavier and might couple easier with vibrations involving predominantly heavy atoms); this coupling can then lead to the observed frequency shifts for these vibrations in the deuterated molecules.
In the spectral range ca. $1500-1300 \mathrm{~cm}^{-1}$ one can find essentially four low-intensity bands whose behavior is very informative. All these bands undergo dramatic changes upon cooling and isotopic substitution. Lowering the temperature leads to a remarkable narrowing effect and to a substantially better resolved band structure. The bands at 1475 and $1423 \mathrm{~cm}^{-1}$ are shifted to higher frequencies by ca. 4 and $3 \mathrm{~cm}^{-1}$, respectively, whereas the peak at $1352 \mathrm{~cm}^{-1}$ is red-shifted by $2 \mathrm{~cm}^{-1}$ and the peak at $1309 \mathrm{~cm}^{-1}$ essentially remains unchanged with temperature. All these bands vanish in the isotopically doped DNAM, meaning that they have a prevailing contribution from a proton in-plane bending coordinate. This assignment is supported by observation of the corresponding ND in-plane vibration bands in the deuterated samples, at frequencies that 
TABLE 1: Average Values of Some Geometrical Parameters for the Structures Whose Geometries Were Optimized by the MP2 and B3LYP Methods, with the Indicated Basis Sets ${ }^{a}$

\begin{tabular}{|c|c|c|c|c|c|c|c|c|}
\hline \multirow[b]{2}{*}{ basis set } & \multicolumn{2}{|c|}{$\mathrm{WB} / \AA$} & \multicolumn{2}{|c|}{ WT/deg } & \multicolumn{2}{|c|}{ LS1/deg } & \multicolumn{2}{|c|}{ LS2/deg } \\
\hline & MP2 & B3LYP & MP2 & B3LYP & MP2 & B3LYP & MP2 & B3LYP \\
\hline 6-31G(d,p) & 1.378 & 1.380 & 0.00 & 0.00 & 0.00 & 0.00 & 0.00 & 0.00 \\
\hline $6-31 G+(d, p)$ & 1.380 & 1.380 & 8.68 & 0.10 & 23.60 & 5.13 & -23.60 & 0.00 \\
\hline $6-31 G++(d, p)$ & 1.380 & 1.380 & 8.83 & 0.10 & 23.72 & 4.82 & -23.72 & -4.82 \\
\hline $6-311 \mathrm{G}(\mathrm{d}, \mathrm{p})$ & 1.379 & 1.380 & 0.00 & 0.00 & 26.05 & 0.00 & -26.05 & 0.00 \\
\hline $6-311 G+(d, p)$ & 1.381 & 1.379 & 9.60 & 0.16 & 31.84 & 12.75 & -31.84 & -12.75 \\
\hline $6-311 \mathrm{G}++(\mathrm{d}, \mathrm{p})$ & 1.381 & 1.379 & 9.58 & 0.19 & 32.10 & 13.04 & -32.10 & -13.04 \\
\hline
\end{tabular}

${ }^{a} \mathrm{WB}$ - weighted average ring bond distance; WT = weighted average absolute torsion angle; LS1 = angle between the ring least squares (LS) plane and the C4 substituent LS plane; LS2 = angle between the ring LS plane and the C6 substituent LS plane.

give rise to the appropriate isotopic ratios (see also Figure 6): $1040 \mathrm{~cm}^{-1}$ (isotopic ratio: $1475 / 1040=1.418$ ), $990 \mathrm{~cm}^{-1}$ $(1423 / 990)=1.437)$; the doublet at 953 and $945 \mathrm{~cm}^{-1}$ (isotopic ratios: $1352 / 953=1.419$ and $1309 / 945=1.385$, respectively); and possibly the very low-intensity peak at $885 \mathrm{~cm}^{-1}$ (isotopic ratio: $1309 / 885=1.447$ ).

We ascribe the strong band centered at $1256 \mathrm{~cm}^{-1}$ in the spectra of DNAM-h to the $v_{\mathrm{s}}\left(\mathrm{NO}_{2}\right)$ vibrational mode (which, according to the theoretical predictions, appears to be coupled with the azo stretching vibration, $v(\mathrm{NN}))$. This band exhibits no shift with temperature, and only a slight increase in its intensity is observed. Its profile is quite affected upon deuteration, which can be explained by the additional contribution to this spectral range of the ND in-plane bending modes in the DNAM-d samples. In the study on 3,5-diamino-1-nitroamidino1,2,4-triazole, Astakhov et al. ${ }^{32}$ described a band in the spectral range $1276-1274 \mathrm{~cm}^{-1}$ as belonging to the $v_{\mathrm{s}}\left(\mathrm{NO}_{2}\right)$ mode.

Finally, a peak is observed at $1197 \mathrm{~cm}^{-1}$ that remains unchanged upon both temperature change and deuteration. Accordingly to the calculations, this feature is mainly ascribable to one in-plane ring deformation, predicted at $1189 \mathrm{~cm}^{-1}$. Our computations also provided a value of $1032 \mathrm{~cm}^{-1}$ for a combination of the $v_{\mathrm{s}}\left(\mathrm{NO}_{2}\right)$ and $\delta(\mathrm{N} 5 \mathrm{H})$ modes. The corresponding experimental feature is probably the very low-intensity peak at $1060 \mathrm{~cm}^{-1}$, which is slightly changed upon deuteration.

3.1.3. Spectral Range $1000-400 \mathrm{~cm}^{-1}$. The spectra of crystalline DNAM-h and of its deuterium doped counterpart in the $1000-400 \mathrm{~cm}^{-1}$ region are shown in Figure 6 . The $\mathrm{NH}$ out-of-plane bending mode bands are expected within this spectral range.

The peak frequency position of the band at $919 \mathrm{~cm}^{-1}$ does not change upon cooling. Lowering the temperature causes minor changes in its intensity and a slight modification in its profile. At the lowest temperature, this absorption reveals a complex pattern: the main peak, at $919 \mathrm{~cm}^{-1}$, a shoulder at ca. $923 \mathrm{~cm}^{-1}$ and another one at ca. $908 \mathrm{~cm}^{-1}$. This profile may be interpreted as resulting from mode splitting due to nonequivalence of the four molecules present in the crystalline unit cell of DNAM. However, the most noticeable feature exhibited by the band at $919 \mathrm{~cm}^{-1}$ is that it changes dramatically on isotopic exchange. At first sight, this behavior suggests a protonic character for this band, and thus a plausible assignment would be pure NH out-of-plane bending mode. However, the theoretical calculations (see below) contradict this interpretation. Instead, they are more consistent with this band resulting from a complex contribution of different modes, whose respective molecular fragments, such as the triazine ring, $\mathrm{NN}$ and $\mathrm{NO}_{2}$ moieties, participate in hydrogen bonds.

On the contrary, the effect of the temperature lowering is markedly observed for the band centered at $813 \mathrm{~cm}^{-1}$, which is characterized by a clear intensity enhancement upon cooling. This behavior, combined with the effect of the isotopic exchange, appears to be a paradigmatic case revealing the relevance of using both techniques and allows us to doubtlessly conclude that this band is ascribable to an $\mathrm{NH}$ out-of-plane bending mode. This assignment is also in agreement with the theoretical predictions carried out, mainly from the anharmonic vibrational calculations, whose provided value was $847 \mathrm{~cm}^{-1}$.

The two strong bands at 771 and $763 \mathrm{~cm}^{-1}$ observed in the spectra of DNAM-h exhibit a narrowing and an intensity increase as the temperature is lowered, but the frequencies remain unchanged. The first one shifts only slightly $\left(2 \mathrm{~cm}^{-1}\right)$ to higher frequencies in the spectrum of the sample with higher deuterium content and, accordingly to the calculations, shall be ascribed to vibrations of the $\mathrm{CNN}$ fragment. On the other hand, the peak at $763 \mathrm{~cm}^{-1}$ drastically reduces its intensity upon deuteration. Again, this effect can deceive, because it was found from the theoretical approach that this band is related with the CNN fragment, rather than with an NH out-of-plane mode.

In the spectral range below $763 \mathrm{~cm}^{-1}$, some low-intensity bands with the expected narrowing effect due to the temperature lowering are observed. All of them, probably due to ring vibration modes, are essentially invariant upon deuteration, the band at $698 \mathrm{~cm}^{-1}$, probably due to ring puckering, being the only exception. As observed in Figure 6, this band is practically absent in the DNAM-d sample with $70 \%$ of the doped isotope (trace B).

In short, among the bands within the $1000-400 \mathrm{~cm}^{-1}$ spectral range being clearly sensitive to deuteration, only that at 813 $\mathrm{cm}^{-1}$ was found to be unequivocally ascribable to an out-ofplane bending mode involving the $\mathrm{NH}$ coordinates. Its analogous band in the spectrum of deuterated sample is observed at 580 $\mathrm{cm}^{-1}$, leading to an isotopic ratio of $813 / 580=1.402$. The remaining bands in this spectral region, although exhibiting noticeable sensitivity to isotopic exchange, result essentially from the coalescence of multiple vibrations involving motions of H-bond acceptor moieties in the DNAM molecule.

To conclude this section, it is important to notice the quite modest band shifts globally observed upon temperature decreasing (the largest observed shift was $7 \mathrm{~cm}^{-1}$ ). This kind of thermal response, which has also been recently reported for diazines, ${ }^{69}$ suggests that the crystalline DNAM is only moderately affected upon cooling, and therefore that the intramolecular coordinates would prevail over the intermolecular ones in the manifestation of the vibrational modes. This is one of the reasons why an extensive theoretical study has been performed on the monomeric DNAM in the present work, as described below in detail.

3.2. Computational Results. 3.2.1. Comparison of Methods: MP2 versus DFT. Energetics and Structural Data. To evaluate the dependence of selected vibrational modes on the theoretical method, DFT and ab initio MP2 calculations have been performed, using Pople-type basis sets of increasing size, from $6-31 \mathrm{G}(\mathrm{d}, \mathrm{p})$ to $6-311++\mathrm{G}(\mathrm{d}, \mathrm{p})$, thus substantially improving the quality of the basis sets comparing to our previous work. ${ }^{8}$ 

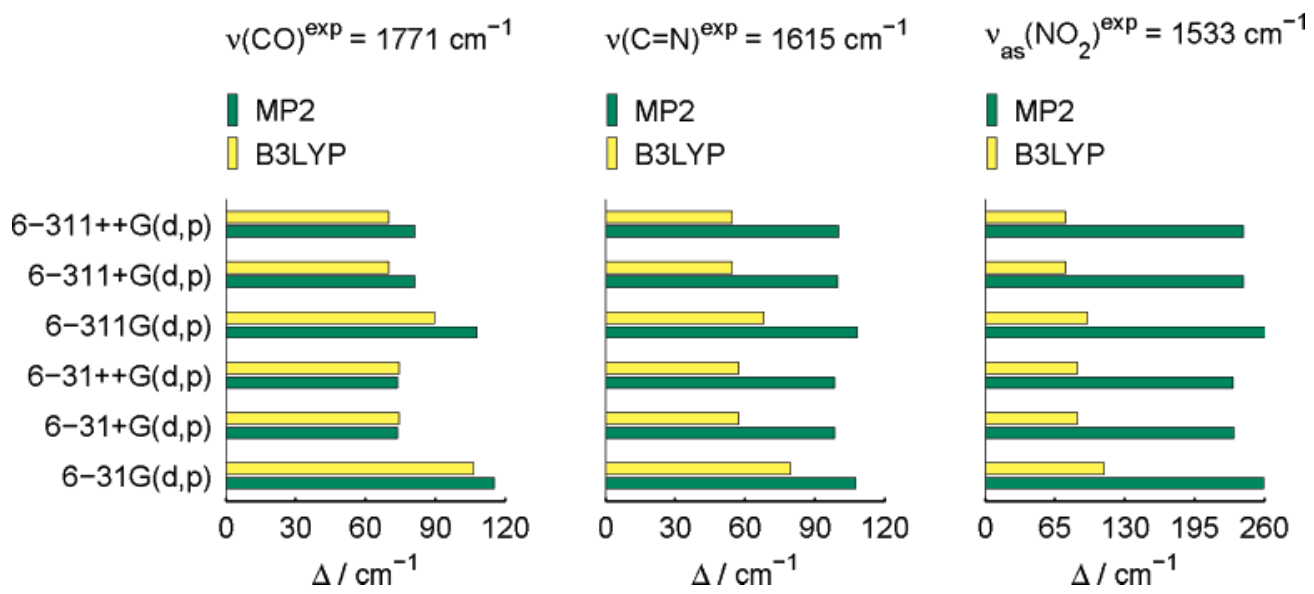

Figure 7. Differences in DNAM vibrational frequencies between selected MP2 and DFT(B3LYP) modes, computed at the indicated levels of theory. Here $\Delta=\tilde{v}^{\exp }-\tilde{v}^{\text {cal }}$, and $\tilde{v}^{\text {exp }}$ corresponds to experimental frequencies (at $10 \mathrm{~K}$ ) and $\tilde{v}^{\text {cal }}$ to their theoretical counterparts.

The detailed results on energetics and the geometric parameters are collected in the Supporting Information. Regarding energies, it can be mentioned that, in spite of the different values predicted by the two methods, the trends followed by the results obtained by the two methods as a function of the basis set are very similar. In each one, the most important variation occurs when double- $\zeta$ basis sets are replaced by their triple- $\zeta$ counterparts. In addition, inclusion of diffuse functions on heavy atoms leads also to remarkable effects on the calculated energies, which in turn are much less influenced by the addition of diffuse functions on hydrogen atoms.

The predicted geometries are summarized in Table 1 in terms of average values for a given type of coordinate. Considering first the results obtained at the MP2 level of theory, no remarkable changes in the calculated bond lengths are found on going from the smallest to the largest basis set. Variations of almost all bond lengths are within a $0.01 \AA$ interval, the exceptions being the covalent bonds involving the nitroimine fragment (e.g., N8-N9, N9-O10 and $\mathrm{N} 9-\mathrm{O} 14$; differences within a $0.02 \AA$ range; see Figure 1 for atom numbering) and the intramolecular hydrogen bond $\mathrm{N} 5-\mathrm{H} \cdots \mathrm{O}$ (variations within a $0.04 \AA$ interval). The more pronounced changes are explained by the distortion of the nitroimine substituents in relation to the ring plane (see Table 1). In fact, although the valence angles do not change more than by $2^{\circ}$ with the basis set, the departures of the nitroimine moieties from the coplanarity with the triazine ring are not negligible. Only with the smallest basis set a $C_{2 v}$ symmetry is predicted, whereas a formal $C_{s}$ symmetry is obtained with the remaining basis sets. The angle between the ring least-squares (LS) plane and the $\mathrm{C} 4$ (or C6) substituent LS plane increases from $23.6^{\circ}(6-31+\mathrm{G}(\mathrm{d}, \mathrm{p})$ basis $)$ to $32.1^{\circ}(6-$ $311++\mathrm{G}(\mathrm{d}, \mathrm{p})$ basis $)$.

The structural data obtained with the B3LYP method are different in some aspects from those calculated by the MP2 method. The changes in the bond lengths with the basis sets are within $0.01 \AA$ for covalent bonds and $0.02 \AA$ for the intramolecular H-bond. Valence angles are essentially invariant with the basis set. Furthermore, a $C_{2 v}$ symmetry is predicted with both the $6-31 \mathrm{G}(\mathrm{d}, \mathrm{p})$ and $6-311 \mathrm{G}(\mathrm{d}, \mathrm{p})$ basis sets. The inclusion of diffuse functions leads to deviations from planarity that are considerably less pronounced than those obtained with the MP2 method. The same applies also to the distortion of the nitroimine substituents regarding the ring LS plane (see Table $1)$.

From these differences some divergencies in the vibrational modes (either pure or combination modes) calculated by both methods can be anticipated, mainly those in which the ring substituents are involved.

Vibrational Data. Turning now toward the discussion of the spectroscopic results, in the following analysis (method and basis set sensitivity), we mainly look for uncertainty limits associated to the theoretical calculations. Without ignoring the relevance of all vibrational modes of DNAM, emphasis will be given to the proton related vibrations. A direct comparison between computed and experimental results will also be made for three vibrational modes whose assignments are unambiguous, in particular $v(\mathrm{CO}), v(\mathrm{C}=\mathrm{N})$ and $v_{\text {as }}\left(\mathrm{NO}_{2}\right)$. For these vibrational modes, it is clear from Figure 7 that the B3LYP outperforms the MP2 method. As expected, all basis sets overestimate the frequencies. However, it is interesting to note that, within the basis set range considered, MP2 systematically predicts the order $v_{\text {as }}\left(\mathrm{NO}_{2}\right)>v(\mathrm{C}=\mathrm{N})$, which contrasts with the B3LYP method. This can explain the quite different predictive quality of the methods under comparison in the case of those three vibrational modes. Although a generalization to other modes cannot be made, these results give some support to the reliability in using the DFT method in the vibrational description of the DNAM system.

Figure 8 compares the $\mathrm{NH}$ stretching and bending modes predicted by the MP2 and B3LYP methods with the Pople's basis of double and triple- $\zeta$ quality, without and with diffuse functions. All basis sets are compared with the largest basis set used $[6-311++\mathrm{G}(\mathrm{d}, \mathrm{p})]$. The variation with the basis sets is more pronounced for the MP2 than for the B3LYP method, indicating the faster convergence of this latter method. Adding diffuse functions to hydrogen atoms essentially makes no diference in both cases. However, the diffuse functions on the heavy atoms play an important role, this effect being more pronounced in the case of the stretching, $v(\mathrm{NH})$, and out-of-plane, $\gamma(\mathrm{NH})$, modes. In fact, within the range of basis sets under consideration, the predicted proton vibration frequencies are more sensitive to the inclusion of heavy atom diffuse functions than to the replacement of double- $\zeta$ by the triple- $\zeta$ basis set. If one excludes the cases not involving diffuse functions, most of the predicted frequencies are within a $20 \mathrm{~cm}^{-1}$ interval, the exception being the stretching modes obtained from the MP2 method in which that interval is doubled. To summarize, the proton-related vibrational modes calculated by the B3LYP method are less sensitive to the basis set than those obtained with the MP2 method.

The absolute values of the vibrational frequencies presented in Figure 8 show that the stretching, $v(\mathrm{NH})$, and in-plane, 

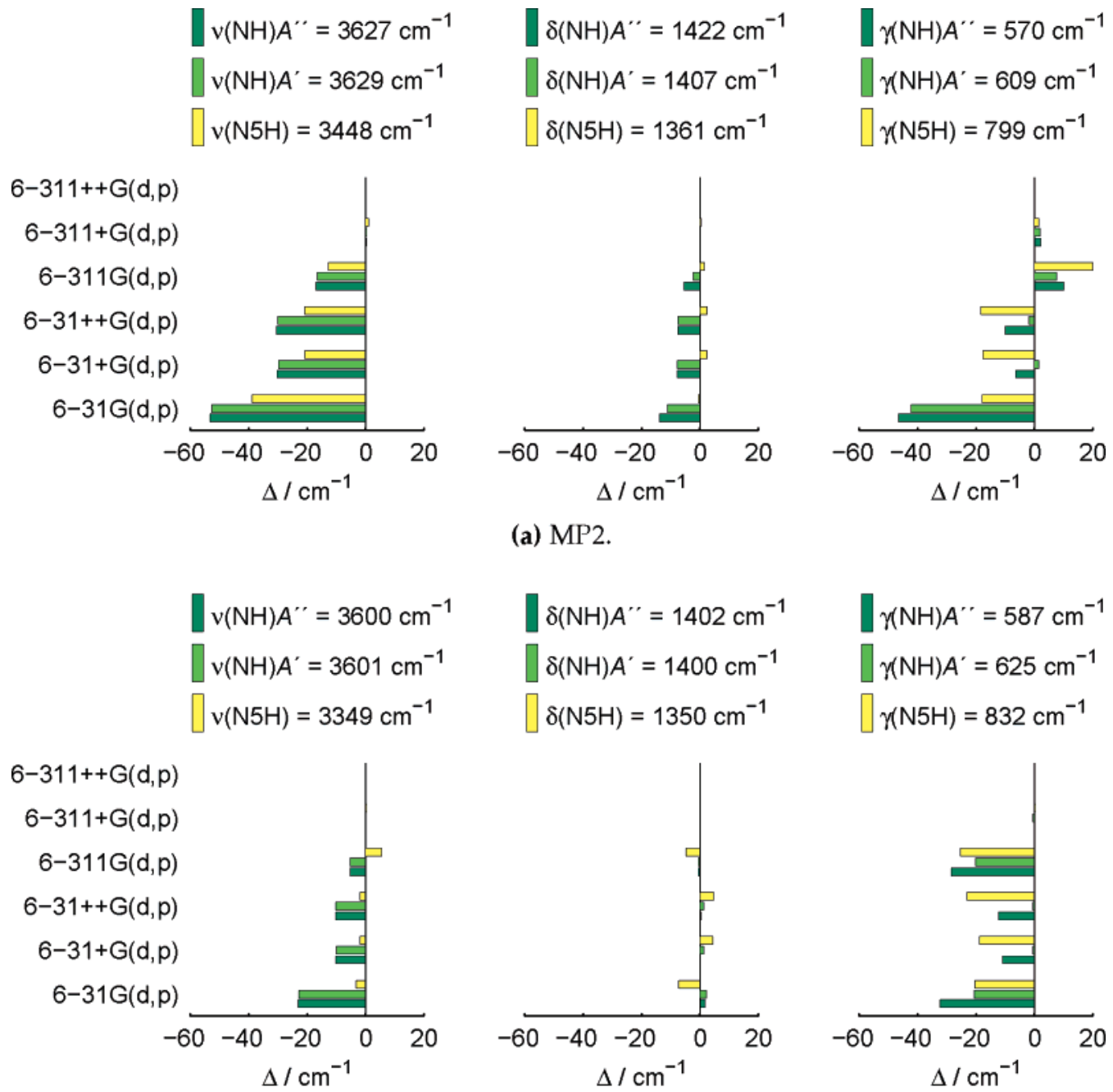

(a) MP2.

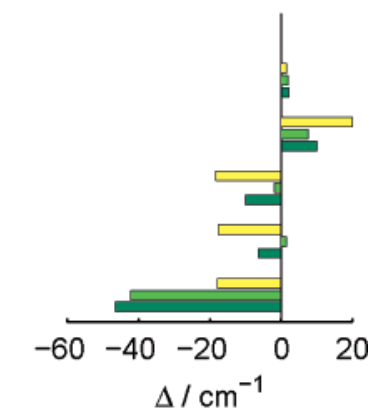

\section{(a) $\mathrm{MP} 2$.}
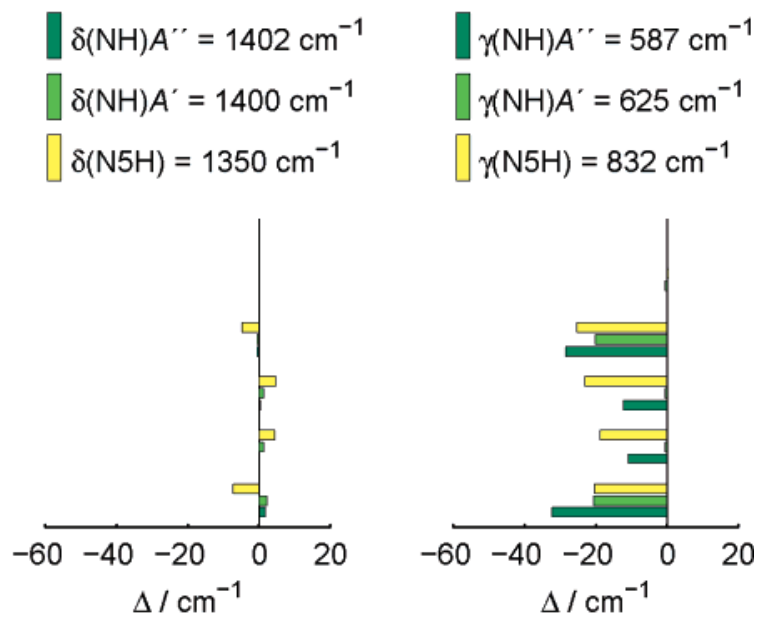

(b) B3LYP.

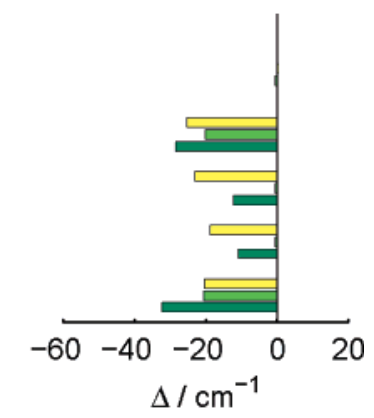

Figure 8. Differences in DNAM vibrational frequencies between selected vibrational modes, computed at the indicated levels of theory. Here $\Delta=\tilde{v}^{\text {ref }}-\tilde{v}$, and $\tilde{v}^{\text {ref }}$ correspond to absolute frequency values calculated with the largest basis set $(6-311 \mathrm{G}++(\mathrm{d}, \mathrm{p}))$ and taken as references.

$\delta(\mathrm{NH})$, frequencies computed using the MP2 method are higher than those predicted by the B3LYP method. On the contrary, the out-of-plane frequencies, $\gamma(\mathrm{NH})$, predicted by the MP2 method are somewhat lower than those calculated at the B3LYP level. Globally, when compared with the B3LYP method, the MP2 method systematically predicts higher values for fundamentals whose frequencies are above ca. $800 \mathrm{~cm}^{-1}$, whereas below this value the opposite trend is generally found.

3.2.2. Basis Set Dependencies from DFT Calculations. Continuing the analysis toward the evaluation of the influence of the theoretical method on the calculated IR spectroscopic data for DNAM, the convergence obtained in the calculated frequencies for some relevant vibrational modes (viz. $v(\mathrm{C}=\mathrm{O})$, $v(\mathrm{C}=\mathrm{N}), v_{\text {as }}\left(\mathrm{NO}_{2}\right)$ and the proton related modes) as a function of the basis set was assessed undertaking extensive DFT calculations with the B3LYP functional in vacuum. In the following paragraphs, one simply outlines the main features revealed by this study.

Figure 9, in which experimental and computed values are compared, suggests that for the selected vibrational modes the results are globally similar. It is worthy to note that the $6-31+\mathrm{G}$ (d,p) and the aug-cc-pVQZ basis sets exhibit quite comparable performances, thus, the former appearing as a good compromise between performance and computational cost. Again, it should be stressed that this analysis cannot be simply extrapolated to the remaining vibrational modes. Nevertheless, they are indica- tive of the adequacy of the DFT (B3LYP) technique for studying the spectroscopic properties of DNAM.

The computed results for the proton-related vibrational modes are summarized in Figure 10. Here, the results are again compared with those resulting from the highest level of theory used (B3LYP/aug-cc-pVQZ). On the whole, the results show that the size and quality of the basis set mostly affect the outof-plane proton bending modes, $\gamma(\mathrm{NH})$. On the other hand, both the stretching, $v(\mathrm{NH})$, and in-plane bending, $\delta(\mathrm{NH})$, modes are much less sensitive to the basis set.

For the same combination of diffuse and polarization functions, the largest variations in magnitude on going from the double to the triple- $\zeta$ basis sets are predicted for the $\gamma(\mathrm{N} 5 \mathrm{H})$ mode, being 18 and $13 \mathrm{~cm}^{-1}$, respectively for Pople's basis set [when $6-31++\mathrm{G}(\mathrm{d}, \mathrm{p})$ is replaced by $6-311++\mathrm{G}(\mathrm{d}, \mathrm{p})$ ] and for its Dunning's basis set counterpart (i.e., when aug-cc-pVDZ is replaced by aug-cc-pVTZ). There are no noticeable differences between the results obtained with triple and quadruple- $\zeta$ quality basis sets of the Dunning-type. Within the Pople-type double- $\zeta$ grouping, the inclusion of diffuse functions on heavy atoms leads to noticeable variations in the calculated frequencies for the $\gamma(\mathrm{NH})$ modes. The most representative vibration is again the $\gamma(\mathrm{N} 5 \mathrm{H})$ mode, which exhibits a variation of $30 \mathrm{~cm}^{-1}$ (for the pair 6-311G(2d,p) and 6-311+G(2d,p)), whereas the frequencies 


$$
\begin{aligned}
& \square v(C O)^{\exp }=1771 \mathrm{~cm}^{-1} \\
& \square v(\mathrm{C}=\mathrm{N})^{\exp }=1615 \mathrm{~cm}^{-1} \\
& \square v_{\mathrm{as}}\left(\mathrm{NO}_{2}\right)^{\exp }=1533 \mathrm{~cm}^{-1}
\end{aligned}
$$

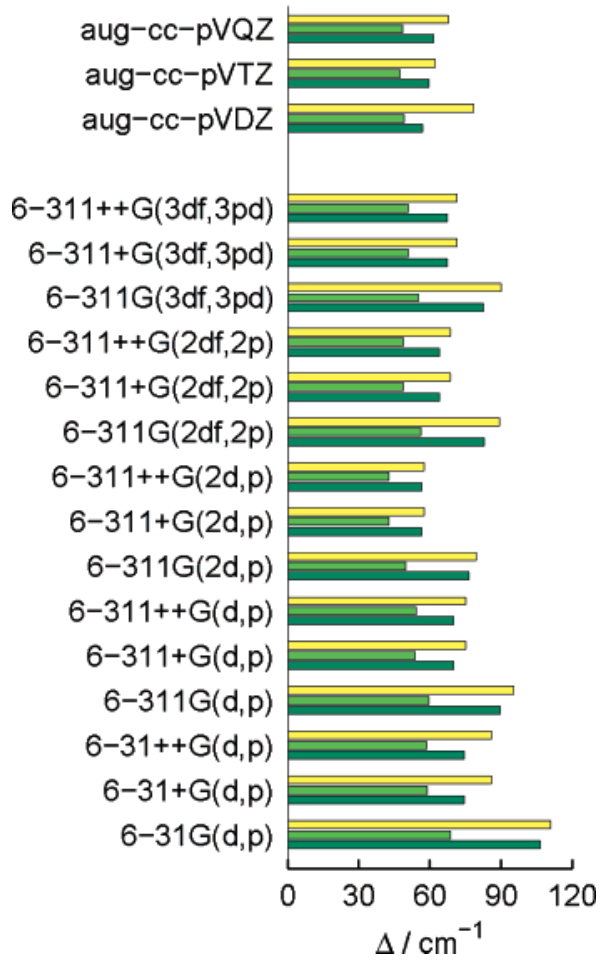

Figure 9. Basis set dependencies of selected vibrational modes of DNAM, calculated with the B3LYP functional in vacuum. Here $\Delta=\tilde{v}^{\exp }-\tilde{v}^{\text {cal }}$, and $\tilde{v}^{\exp }$ correspond to experimental frequencies (at 10 $\mathrm{K})$ and $\tilde{v}^{\text {cal }}$ to their theoretical counterparts.

of the $v(\mathrm{NH})$ and $\delta(\mathrm{NH})$ modes exhibit only marginal fluctuations (less than $7 \mathrm{~cm}^{-1}$ for most cases) due to the inclusion of diffuse functions on heavy atoms. Adding diffuse function to hydrogen atoms has essentially no effect. Concerning the inclusion of multiple polarization functions, the largest effects, in both magnitude and sign, are once more observed for the $\gamma(\mathrm{NH})$ fundamentals, particularly the $\gamma(\mathrm{N} 5 \mathrm{H})$ mode. For instance, on going from $6-311 \mathrm{G}(\mathrm{d}, \mathrm{p})$ to $6-311 \mathrm{G}(2 \mathrm{~d}, \mathrm{p})$ the $\gamma(\mathrm{N} 5 \mathrm{H})$ is red-shifted by $31 \mathrm{~cm}^{-1}$, but for their diffuse variants $(6-311++\mathrm{G}(\mathrm{d}, \mathrm{p})$ to $6-311++\mathrm{G}(2 \mathrm{~d}, \mathrm{p}))$ a blue shift of $25 \mathrm{~cm}^{-1}$ is encountered.

In summary, when compared with the reference values (calculated at the B3LYP/aug-cc-pVQZ level), the proton stretching frequencies, $v(\mathrm{NH})$, computed with basis sets larger than the $6-31 \mathrm{G}(2 \mathrm{~d}, \mathrm{p})$, are within an interval of $15 \mathrm{~cm}^{-1}$. This is reduced to ca. $10 \mathrm{~cm}^{-1}$, or even less, if only diffuse variants are considered, in the case of the in-plane bending frequencies, $\delta(\mathrm{NH})$. On the other hand, the calculated frequencies for the out-of-plane bending modes, $\gamma(\mathrm{NH})$, appear to be consistently closer to those obtained with the largest basis set only from the 6-311+G(2df,2p) basis set.

3.2.3. Environment Dependencies from PCM, Supermolecular Model and Anharmonic Calculations. As mentioned above, X-ray studies ${ }^{8}$ clearly demonstrated the existence of an extensive H-bond network in crystalline DNAM. In each molecule, the $\mathrm{N}-\mathrm{H}$ moiety participates in a bifurcated intermolecular $\mathrm{H}$-bond in which the acceptors are of different type ( $\mathrm{N}$ and $\mathrm{O}$ atoms), whereas the $\mathrm{N} 5-\mathrm{H}$ fragment participates in a symmetric bifurcated intramolecular $\mathrm{H}$-bond with both acceptors being oxygen atoms (see Figure 1). These differences, and cor- respondingly the differences in the associated H-bond lengths, should be manifested in the infrared spectra of DNAM. To simulate the intermolecular interactions, different approaches were used. One consisted in modeling the nearest environment around a given DNAM molecule by placing other DNAM molecules around it, i.e., generating a supermolecular model including up to three molecules of DNAM (see below). The other was by using the polarizable continuum model (PCM) with two different solvents, viz. water and dimethyl sulfoxide, with dielectric constants of 78.39 and 46.7, respectively. Besides these methodologies, a third one was used. As confirmed by the isotopic frequency ratios and their variation presented above, the vibrational frequencies of $\mathrm{NH}$ are expected to be strongly anharmonic and thus not easily obtained by scaling harmonic frequencies. Thus, in the third methodology used, this problem is addressed simultaneously with the H-bonding effects by means of anharmonic vibrational calculations on a DNAM-water complex (see Figure 3).

As initial structures for the optimizations using the PCM method, the optimized geometries obtained for the isolated molecule in vacuum were used. Figure 11 resumes the most relevant results obtained using this approach, at the B3LYP/6$31++\mathrm{G}(\mathrm{d}, \mathrm{p})$ level of theory. It should be noticed that calculations with other basis sets have also been performed within the PCM framework. That evaluation has shown that, like in the vacuum calculations, the $\gamma(\mathrm{NH})$ coordinate appeared to be quite sensitive to the basis set used, both in water and in DMSO media. Nevertheless, considering the overall results, the $6-31++\mathrm{G}(\mathrm{d}, \mathrm{p})$ basis set seemed to be a good compromise for comparison purposes.

As seen in Figure 11, in the case of the $v(\mathrm{NH})$ modes the computed red shifts in frequencies are higher in the more polar solvent (water) than those in the less polar solvent (DMSO). The results for the trimer in vacuum are comparable to the monomer in water. On the other hand, the shifts in the $\mathrm{NH}$ stretching modes are in the same direction both for monomer in solvents and for the central unit of trimer in vacuum. This finding contrasts with the results for the NH in-plane and outof-plane bending modes, where the trimer shows a different behavior, regarding both the direction of the shifts and their magnitude compared to the monomer in solvents. The largest shifts are those predicted for the DNAM-water complex model. Applying anharmonic corrections to this model leads to higher shifts in the NH stretching modes, whereas the opposite is observed in the case of the bending modes. These differences also suggest higher anharmonicities in the stretching modes when compared with the bending modes (the anharmonic results will be discussed below).

It is noteworthy that these theoretical approaches clearly confirm that the "lateral" $\mathrm{NH}$ stretching vibrations are much more prone to a red shift when compared with their "central" $\mathrm{N} 5 \mathrm{H}$ counterpart, which, by contrast, exhibits a quite small shift whatever the chemical environment here considered. In other words, the $\mathrm{N} 5 \mathrm{H}$ proton participates in a medium to strong intramolecular $\mathrm{H}$-bond whose effect seems to prevail over the influence of the external environment, at least in the considered supermolecules, simulating a chain-like (one-dimensional) H-bonded network. This is closely related with the fact that the bonds in the case of $\mathrm{NH}$ are more sensitive to the external environment than the $\mathrm{N} 5 \mathrm{H}$ bond, which remains essentially invariant with the model considered. Although there is a predicted elongation of the $\mathrm{N}-\mathrm{H}$ bonds, a slight shortening is predicted for the intramolecular N5-H (see Figure 12). 


$$
\begin{aligned}
& \operatorname{vv}(\mathrm{NH}) A^{\prime \prime}=3595 \mathrm{~cm}^{-1} \\
& \square v(\mathrm{NH}) A^{\prime}=3596 \mathrm{~cm}^{-1} \\
& \square v(\mathrm{~N} 5 \mathrm{H})=3339 \mathrm{~cm}^{-1}
\end{aligned}
$$

$$
\begin{aligned}
& \gamma(\mathrm{NH}) A^{\prime \prime}=625 \mathrm{~cm}^{-1} \\
& \gamma(\mathrm{NH}) A^{\prime}=649 \mathrm{~cm}^{-1} \\
& \gamma(\mathrm{N} 5 \mathrm{H})=886 \mathrm{~cm}^{-1}
\end{aligned}
$$

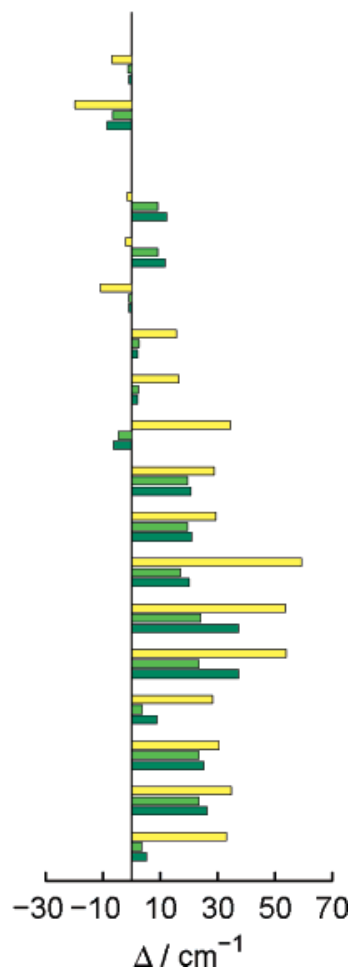

Figure 10. Basis set dependencies of NH vibrational modes of DNAM, calculated with the B3LYP functional in vacuum. Here $\Delta=\tilde{v}^{\text {ref }}-\tilde{v}$, where $\tilde{v}^{\text {ref }}$ correspond to absolute frequency values obtained using the largest basis set (aug-cc-pVQZ), here taken as reference values.
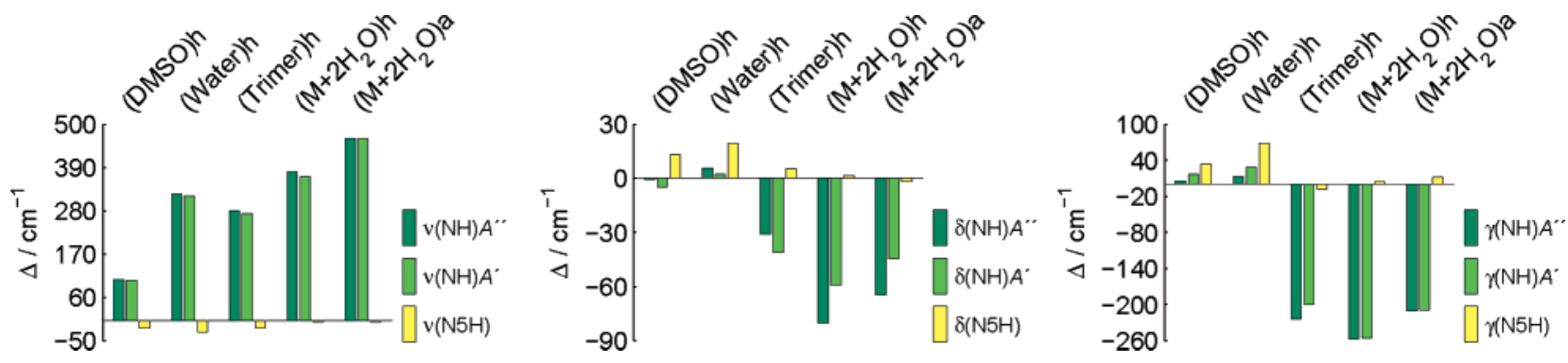

Figure 11. Environmental effect on the proton vibrational modes of DNAM, computed at the B3LYP/6-31+G(d,p) level of theory through different models. The letters $\mathrm{h}$ and a hold for harmonic and anharmonic, respectively. Here $\Delta=\tilde{v}^{\circ}-\tilde{v}^{\mathrm{H}}$, where $\tilde{\nu}^{\mathrm{H}}$ correspond to frequencies of the simulated H-bonded molecule, and $\tilde{v}^{\circ}$ correspond to frequencies of the free molecule, which are $v(\mathrm{NH}) \mathrm{A}^{\prime}=3611, v(\mathrm{NH}) \mathrm{A}^{\prime \prime}=3610, v(\mathrm{~N} 5 \mathrm{H})=$ $3351, \delta(\mathrm{NH}) \mathrm{A}^{\prime \prime}=1402, \delta(\mathrm{NH}) \mathrm{A}^{\prime}=1399, \delta(\mathrm{N} 5 \mathrm{H})=1346, \delta(\mathrm{N} 5 \mathrm{H})=851, \delta(\mathrm{NH}) \mathrm{A}^{\prime}=626$, and $\delta(\mathrm{NH}) \mathrm{A}^{\prime \prime}=599 \mathrm{~cm}^{-1}$.

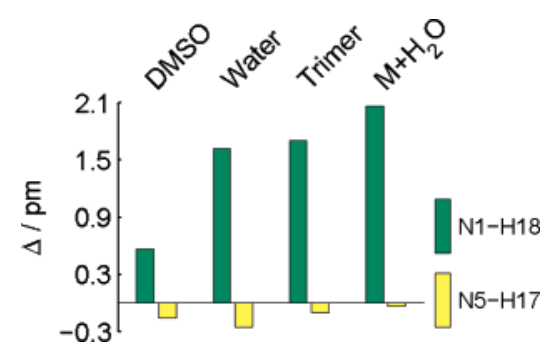

Figure 12. Environment effect on the $\mathrm{N}-\mathrm{H}$ bond lengths in DNAM, computed at the B3LYP/6-31+G(d,p) level. Here $\Delta=d^{\circ}-d^{\mathrm{H}}$, where $d^{\circ}$ corresponds to bond lengths of free molecule and $d^{\mathrm{H}}$ to bond lengths of simulated H-bonded molecule.

As mentioned in the Introduction, crystalline DNAM is organized into chains (similar to those shown in Figure 1). A simple theoretical model allows us to simulate spectra of short
DNAM chains consisting of a few monomer links. In this model, we optimized structures for systems consisting of two and three DNAM molecules and compared their vibrational spectra with those of the monomer (see Figure 13). Because the supermolecular DNAM systems are stabilized by intermolecular hydrogen bonds, this approach allows us to distinguish between spectral signatures of proton-related modes originating in free (termini of chain) and hydrogen-bonded $\mathrm{NH}$ groups (inside the chain). In the $\mathrm{NH}$ stretching region, the calculated spectrum of the monomer exhibits two weak absorption bands centered approximately at 3600 and $3350 \mathrm{~cm}^{-1}$ (Figure 13, frame a, trace $\mathrm{M})$. The higher frequency feature originates in two $\mathrm{NH}$ groups not involved in hydrogen bonding. Upon an increase of the chain size, this feature persists in the spectra, and corresponds to the vibrations of the two terminal NH groups of the supermolecule. The NH groups enclosed in the middle of dimer and trimer 

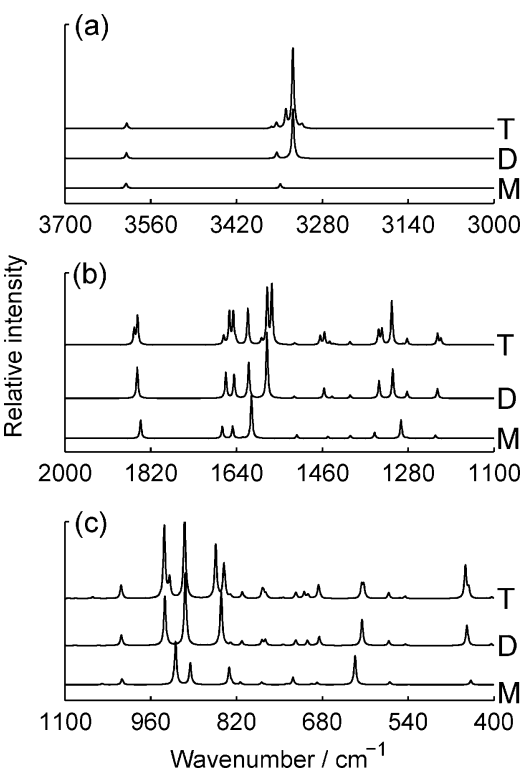

Figure 13. Comparison of calculated IR spectra of monomeric DNAM and supermolecular models including two and three units, calculated at the B3LYP/6-311+G(d,p) level. M, D, and T stand for monomer, dimer, and trimer, respectively. Calculated frequencies are not scaled, spectra were shifted on ordinate for clarity.

become involved in the intermolecular hydrogen bonding interactions and give rise to new striking features in the calculated spectra. For the NH stretching modes these features emerge at ca. $3330 \mathrm{~cm}^{-1}$ and are characterized by very high infrared intensities (Figure 13, frame a, traces D and T). These intensities strongly increase with the size of the chain and completely dominate the vibrational spectrum in this range already in such a small aggregate as the trimer. Visualization of the corresponding normal modes shows that the high-intensity bands originate in the collective motions of inner $\mathrm{NH}$ groups. The characteristic change of spectral intensities exhibited by the NH stretching vibrations in the sequence "monomerdimer-trimer" also facilitated the assignment of the $\mathrm{NH}$ inplane and out-of-plane bending vibrations in supermolecules. Such modes were predicted to appear at ca. 1575 and $855 \mathrm{~cm}^{-1}$ (see Figure 13, frames $\mathrm{b}$ and $\mathrm{c}$ ). These calculations proved to be very useful in assignments of proton-related vibrational modes in the experimental spectra (see below).

Another group of bands turned to be much less sensitive, in terms of infrared intensities, to the presence of intermolecular interactions. These bands originate in vibrations of the groups not directly involved in the hydrogen bonding, such as the $\mathrm{C}=\mathrm{O}$ and $\mathrm{C}=\mathrm{N}$ groups (see bands in the $1850-1600 \mathrm{~cm}^{-1}$ region, Figure 13, frame b). A weak dependence of the corresponding vibrations upon the size of the supermolecule suggests that these vibrational modes (like $\mathrm{C}=\mathrm{O}$ and $\mathrm{C}=\mathrm{N}$ stretching) in the experimental spectra of the crystals can be successfully interpreted on the basis of the theoretical data calculated at the monomeric level.

3.3. Spectral Assignments. Among the 48 normal mode vibrations expected for an isolated molecule of DNAM we will consider only those within the spectral range experimentally analyzed, i.e., 4000-400 $\mathrm{cm}^{-1}$. Table 2 summarizes the experimental frequencies and their theoretical counterparts. Some modes could not be observed experimentally by virtue of the respective dipole transitions not being strong enough. The plenty of theoretical results described above give us a valuable support to extend the assignments to modes other than those already mentioned in section 3.1. The calculated results presented in Table 2 are restricted to the harmonic and anharmonic values obtained from the DNAM-water complex (Figure 3) at the RB3LYP/6-31+G(d,p) level.

In each DNAM molecule, two of the three protons occupy equivalent positions. Thus, two stretching vibrations-symmetric $\left(\mathrm{A}^{\prime}\right)$ and antisymmetric modes $\left(\mathrm{A}^{\prime \prime}\right)$ - are expected for each equivalent $\mathrm{NH}$ group, plus one stretching vibration due to the $\mathrm{N} 5 \mathrm{H}$ moiety. The sequence $v(\mathrm{~N} 5 \mathrm{H})>v(\mathrm{NH}) \mathrm{A}^{\prime}>v(\mathrm{NH}) \mathrm{A}^{\prime \prime}$ was predicted by all theoretical calculations in which the intermolecular H-bonding effect was accounted, i.e., whenever $\mathrm{H}$-bonds were explicitly included in the theoretical model run in vacuum, as well as for high polar media (i.e., water) in the case of PCM calculations. This makes plausible to tentatively assign the shoulder at $3246 \mathrm{~cm}^{-1}$ to the $v(\mathrm{~N} 5 \mathrm{H})$ mode. On the other hand, the complex and strong couplings that would be present in the solid phase (as suggested by the supermolecular model here used), makes the distinction between the symmetric and antisymmetric modes in a single molecule of limited practical value within this spectral range. Thus, we can only ascribe the bands at 3223 and $3087 \mathrm{~cm}^{-1}$ to collective $v(\mathrm{NH})$ modes but we are unable to unequivocally identify the actual origin of each one. In fact, a detailed interpretation of this spectral region is not trivial. The disagreement between calculated frequencies an experiments is notorious. The computed harmonic frequencies clearly overestimate the experimental findings. On the other hand, the discrepancies between the harmonic and anharmonic results are dramatic. Even the anharmonic calculations led to quite poor predictions, underestimating the actual frequencies. It may be argued that the model has its own limitations in the way the nearest environment of $\mathrm{NH}$ groups is simulated (one DNAM molecule bonded to water through a single $\mathrm{H}$-bond versus two neighboring DNAM molecules interacting via bifurcated $\mathrm{H}$-bonds). But this might not be the case for the $\mathrm{N} 5 \mathrm{H}$ moiety, whose weaker sensitivity to the environment has been substantially suggested from all calculations here reported. However, assuming the proposed assignment as correct, the N5H stretching mode is also badly described by the anharmonic approach, the percentage of deviation between computed and experimental values being about 4.7 (against about 3.4 in the harmonic case). These discrepancies can be understood to some extent in the light of reported results ${ }^{45}$ where it was raised the question of knowing if "problems related to the NH moiety are due to the limits of a low-order perturbative treatment of vibrations or to an intrinsic deficiency of the DFT model".

Fortunately, despite some not negligible differences between calculated and experimental frequencies, the assignments within the remaining spectral range pose no serious difficulties (see Table 2). In general, the anharmonic computation outperforms the harmonic computation in the range $2000-600 \mathrm{~cm}^{-1}$, but the differences are not significant. Below $600 \mathrm{~cm}^{-1}$ the anharmonic approach worsens the frequency predictions, the $\delta(\mathrm{CO})$ vibrational mode being an exception.

The anharmonic correction provides a quite good enhancement in the results for stretching vibrations involving the $\mathrm{C}=\mathrm{O}, \mathrm{C}=\mathrm{N}$, and $\mathrm{NO}_{2}$ (antisymmetric) moieties (compare also with Figures 7 and 9). The errors are about 1.5\%, whereas for the harmonic calculations they are in the range of about 3.7$4.3 \%$.

The assignment of spectral features related with $\mathrm{NH}$ in-plane pure bending modes is substantiated by their behavior upon isotopic exchange (see Figure 5). The agreement between the computed and the experimental values is also quite remarkable. This holds for both anharmonic and harmonic results, with 
TABLE 2: Harmonic $\left(\tilde{v}_{\mathrm{h}}\right)$ and Anharmonic $\left(\tilde{v}_{\mathrm{a}}\right)$ Frequencies Calculated for the DNAM-Water Complex (Figure 3) at the Level of Theory RB3LYP/6-31+G(d,p) and Observed Values $\left(\tilde{v}_{\text {obs }}\right)$ at $10 \mathrm{~K}$

\begin{tabular}{|c|c|c|c|c|}
\hline$\tilde{v}_{\mathrm{h}} / \mathrm{cm}^{-1}$ & calc. intens $/\left(\mathrm{km} \mathrm{mol}^{-1}\right)$ & $\tilde{v}_{\mathrm{a}} / \mathrm{cm}^{-1}$ & $\tilde{\nu}_{\mathrm{obs}} / \mathrm{cm}^{-1}$ & assignments $^{a}$ \\
\hline 3353 & 194 & 3094 & 3247 & $v(\mathrm{~N} 5 \mathrm{H})$ \\
\hline 3245 & 446 & 2982 & 3224 & $\nu(\mathrm{NH})$ \\
\hline 3231 & 1555 & 2981 & 3087 & $v(\mathrm{NH})$ \\
\hline 1840 & 754 & 1797 & 1771 & $v(\mathrm{C}=\mathrm{O})$ \\
\hline 1676 & 602 & 1638 & 1615 & $\nu(\mathrm{C}=\mathrm{N}) \mathrm{A}^{\prime \prime}+\delta(\mathrm{N} 5 \mathrm{H})+\delta(\mathrm{NH}) \mathrm{A}^{\prime \prime}$ \\
\hline 1663 & 417 & 1618 & 1594 & $v(\mathrm{C}=\mathrm{N}) \mathrm{A}^{\prime}+\delta(\mathrm{NH}) \mathrm{A}^{\prime}$ \\
\hline 1628 & 9 & 1591 & & $v_{\mathrm{as}}\left(\mathrm{NO}_{2}\right) \mathrm{A}^{\prime}$ \\
\hline 1612 & 1516 & 1572 & 1533 & $v_{\mathrm{as}}\left(\mathrm{NO}_{2}\right) \mathrm{A}^{\prime \prime}+\delta(\mathrm{NH}) \mathrm{A}^{\prime \prime}$ \\
\hline 1531 & 51 & 1489 & & $v($ ring $) \mathrm{A}^{\prime}$ \\
\hline 1482 & 252 & 1439 & 1475 & $\delta(\mathrm{NH}) \mathrm{A}^{\prime \prime}$ \\
\hline 1458 & 270 & 1412 & 1423 & $\delta(\mathrm{NH}) \mathrm{A}^{\prime}$ \\
\hline 1452 & 33 & 1407 & 1352 & $\delta(\mathrm{NH}) \mathrm{A}^{\prime \prime}+\delta(\mathrm{N} 5 \mathrm{H})+\delta($ ring $)$ \\
\hline 1344 & 277 & 1320 & 1309 & $\delta(\mathrm{N} 5 \mathrm{H})$ \\
\hline 1314 & 984 & 1271 & 1256 & $v_{\mathrm{s}}\left(\mathrm{NO}_{2}\right) \mathrm{A}^{\prime}+v(\mathrm{NN}) \mathrm{A}^{\prime}$ \\
\hline 1312 & 5 & 1266 & & $v($ ring $) \mathrm{A}^{\prime \prime}$ \\
\hline 1222 & 143 & 1189 & 1197 & $v($ ring $) \mathrm{A}^{\prime \prime}+v(\mathrm{C}=\mathrm{N}) \mathrm{A}^{\prime \prime}+v(\mathrm{NN}) \mathrm{A}^{\prime \prime}+\delta(\mathrm{N} 5 \mathrm{H})+v_{\mathrm{s}}\left(\mathrm{NO}_{2}\right) \mathrm{A}^{\prime \prime}$ \\
\hline 1113 & 8 & 1081 & & $v($ ring $)+\delta(\mathrm{NH}) \mathrm{A}^{\prime}$ \\
\hline 1048 & 10 & 1032 & 1060 & $\nu_{\mathrm{s}}\left(\mathrm{NO}_{2}\right) \mathrm{A}^{\prime \prime}+\delta(\mathrm{N} 5 \mathrm{H})$ \\
\hline 1011 & 21 & 989 & & $\delta$ (ring) $A^{\prime}$ \\
\hline 936 & 224 & 912 & 919 & $\delta($ ring $)+v(\mathrm{NN}) \mathrm{A}^{\prime}+\delta\left(\mathrm{NO}_{2}\right) \mathrm{A}^{\prime}$ \\
\hline 920 & 85 & 891 & 907 & $v(\mathrm{NN}) \mathrm{A}^{\prime \prime}+\delta(\mathrm{N} 5 \mathrm{H})+\delta\left(\mathrm{NO}_{2}\right) \mathrm{A}^{\prime \prime}$ \\
\hline 882 & 241 & 847 & 813 & $\gamma(\mathrm{NH}) \mathrm{A}^{\prime}+\gamma(\mathrm{N} 5 \mathrm{H})$ \\
\hline 856 & 0 & 824 & & $\gamma(\mathrm{NH}) \mathrm{A}^{\prime \prime}$ \\
\hline 847 & 1 & 841 & & $\gamma(\mathrm{N} 5 \mathrm{H})+\gamma(\mathrm{NH}) \mathrm{A}^{\prime}$ \\
\hline 831 & 9 & 817 & & $\delta(\mathrm{CNN}) \mathrm{A}^{\prime}$ \\
\hline 812 & 24 & 800 & 771 & $\delta(\mathrm{CNN}) \mathrm{A}^{\prime \prime}$ \\
\hline 774 & 39 & 772 & 763 & $\tau(\mathrm{CNN}) \mathrm{A}^{\prime}$ \\
\hline 771 & 0 & 770 & & $\tau(\mathrm{CNN}) \mathrm{A}^{\prime \prime}$ \\
\hline 745 & 1 & 728 & & $\delta\left(\mathrm{NO}_{2}\right) \mathrm{A}^{\prime}+\delta(\mathrm{CNN}) \mathrm{A}^{\prime}$ \\
\hline 716 & 4 & 712 & & $\gamma(\mathrm{C} 2) \mathrm{A}^{\prime}$ \\
\hline 700 & 7 & 691 & & $\gamma(\mathrm{NNO}) \mathrm{A}^{\prime \prime}+\delta$ (ring) \\
\hline 695 & 0 & 699 & & ring puckering $\mathrm{A}^{\prime \prime}$ \\
\hline 688 & 46 & 732 & 698 & ring puckering $\mathrm{A}^{\prime}$ \\
\hline 581 & 18 & 573 & 584 & $\delta$ (ring) $\mathrm{A}^{\prime}$ \\
\hline 559 & 0 & 535 & 531 & $\delta(\mathrm{CO})$ \\
\hline 439 & 148 & 430 & 445 & $\delta$ (ring) $\mathrm{A}^{\prime \prime}$ \\
\hline
\end{tabular}

percentage deviations from experimental ranging from 0.8 to 2.5 (anharmonic) and 0.5 to 2.7 (harmonic). This finding substantiates the previously stated low sensitivity of the $\mathrm{NH}$ in-plane bending modes to the level of theory (see Figure 10). However, an inferior result is found when the mixed mode involving contributions from $\delta(\mathrm{NH}) \mathrm{A}^{\prime \prime}, \delta(\mathrm{N} 5 \mathrm{H})$ and $\delta($ ring) modes is considered. In this case, deviations from experiments of about $4.1 \%$ (anharmonic) and $7.3 \%$ (harmonic) were obtained.

The results from theoretical calculations clearly suggest that the bands centered at 1256,1197, 1060, and $919 \mathrm{~cm}^{-1}$, as well as the shoulder at ca. $907 \mathrm{~cm}^{-1}$, mainly arise from mixed vibrational modes, as indicated in Table 2. Within this spectral region, the anharmonic correction (ca. $0.8-2.6 \%$ deviation from experiment) still outperforms the harmonic calculation (ca. 1.2$4.6 \%$ deviation from experiment). It is worthy to remind here the sensitivity of the band with peak frequency at $919 \mathrm{~cm}^{-1}$ to isotopic substitution (see Figure 6). This experimental finding can be explained by the fact that molecular fragments contributing to the mixed vibrational mode are involved in H-bonds as acceptor groups. Due to the endocyclic nature of all hydrogens in DNAM, they are prone to be affected by distortions of the triazine ring. On the other hand, oxygen and nitrogen atoms from nitroimine group are H-bond acceptors, and thus any motion involving moieties within the nitroimine group can directly influence the motion of the proton.

Whatever the model used, the performed calculations indicate a strong mixing of the out-of-plane bending modes. Some of them exhibit very small dipole transitions, as evidenced by the modest calculated intensities. These findings helped us to assign the band centered at $813 \mathrm{~cm}^{-1}$ to a mixed mode based on the contribution of both $\gamma(\mathrm{NH}) \mathrm{A}^{\prime}$ and $\gamma(\mathrm{N} 5 \mathrm{H})$ vibrations. The percentage deviation from experimental data is ca. 4.2 and 8.5, respectively, with and without anharmonic correction. These are among the worst deviations found in this analysis. The imprecise description of the NH out-of-plane modes was already evidenced in the computed results summarized in Figure 10.

The most interesting features in the spectral region below ca. $800 \mathrm{~cm}^{-1}$ are probably those corresponding to the bands with peak frequencies at 763 and $698 \mathrm{~cm}^{-1}$. As stressed before, these bands clearly vanished upon deuteration (see Figure 6). Taking into account the spectral range under analysis, a reasonable interpretation of such a behavior could be to ascribe them to a proton vibration mode, possibly $\gamma(\mathrm{NH})$ and/or $\gamma(\mathrm{N} 5 \mathrm{H})$. However, the performed calculations clearly suggest that the modes underlying those frequencies are due to CNN and ring fragments. The explanation for the sensitivity to isotopic exchange was already given above. The theoretical results also show that the anharmonic correction deteriorates the quality of the calculated frequencies in this spectral region.

\section{Conclusion}

This paper reports the results of a comprehensive study of the vibrational spectra of the energetic material 4,6-bis(nitroimine)-1,3,5-triazinan-2-one (DNAM). Variable temperature FTIR spectroscopy $\left(4000-400 \mathrm{~cm}^{-1}\right)$ was applied to natural and isotopically substituted (deuterated) samples of crystalline DNAM. A thorough theoretical study based on 
accurate quantum chemical calculations was performed toward understanding the IR spectral features of DNAM in the condensed phase. The obtained results, both experimental and theoretical, could successfully reveal detailed IR features, and plausible assignments were made possible for the first time. A collection of new spectroscopic data on DNAM is now available. The overall data provided by this study can help in the interpretation of the vibrational spectra of related compounds, thus contributing to a better understanding of the fundamental chemistry of energetic nitroimines.

Supporting Information Available: Tables of total and relative energies, geometrical parameters, and isotopic ratios. Figures of IR spectra. This material is available free of charge via the Internet at http://pubs.acs.org.

\section{References and Notes}

(1) Fried, L.; Manaa, M.; Pagoria, P.; Simpson, R. Annu. Rev. Mater. Res. 2001, 31, 291 .

(2) Shastin, A.; Godovikova, T.; Korsunskii, B. Russ. Chem. Rev. 2003 72,279

(3) Atkinson, E. R. J. Am. Chem. Soc. 1951, 73, 4443.

(4) Raczyńska, E.; Kosińska, W.; Ośmiałowski, B.; Gawinecki, R. Chem. Rev. 2005, 105, 3561-3612.

(5) Simões, P. N.; Pedroso, L. M.; Portugal, A. A.; Campos, J. L. Thermochim. Acta 2000, 364, 71.

(6) Simões, P.; Pedroso, L.; Carvalheira, P.; Campos, J.; Portugal, A. Propellants, Explos., Pyrotech. 2001, 26, 273.

(7) Simões, P.; Pedroso, L.; Plaksin, I.; Campos, J.; Portugal, A. Propellants, Explos., Pyrotech. 2001, 26, 278.

(8) Simões, P.; Pedroso, L.; Matos Beja, A. M.; Ramos Silva, M.; MacLean, E.; Portugal, A. J. Phys. Chem. A 2007, 111, 150.

(9) Murmann, R.; Glaser, R.; Barnes, C. J. Chem. Crystallogr. 2005, 35,317 .

(10) Metelkina, E. Russ. J. Org. Chem. 2005, 40, 543.

(11) Türker, L. J. Mol. Struct. (THEOCHEM) 2004, 681, 177.

(12) Vasiliev, A.; Astakhov, A.; Molokeev, M.; Kruglyakova, L.; Stepanov, R. J. Struct. Chem. 2004, 45, 532.

(13) Vasiliev, A.; Astachov, A.; Molokeev, M.; Kruglyakova, L.; Stepanov, R. Acta Crystallogr., Sect. E 2003, 59, 193.

(14) Vasiliev, A.; Astachov, A.; Molokeev, M.; Kruglyakova, L.; Stepanov, R. Acta Crystallogr., Sect. C 2003, 59, 550

(15) Astrat'yev, A.; Dashko, D.; Kuznetsov, L. Russ. J. Org. Chem. $\mathbf{2 0 0 3}, 31,501$

(16) Astakhov, A. M.; Vasil'ev, A.; Molokeev, M.; Kekin, Y.; Kruglyakova, L.; Stepanov, R. J. Struct. Chem. 2003, 44, 326.

(17) Vasiliev, A.; Astachov, A.; Nefedov, A.; Kruglyakova, L.; Stepanov, R. Acta Crystallogr., Sect. C 2001, 57, 625.

(18) Bracuti, A. J. Chem. Crystallogr. 1999, 29, 671-676.

(19) Rice, S.; Cheng, M.; Cramer, R.; Mandel, M.; Mower, H.; Seff, K. J. Am. Chem. Soc. 1984, 106, 239.

(20) Oszust, J.; Baran, J.; Pietraszko, A.; Drozd, M.; Talik, Z. Spectrochim. Acta, Part A 2005, 62, 773

(21) Laihia, K.; Kolehmainen, E.; Virtanen, E.; Nissinen, M.; Puszko, A.; Talik, Z. Magn. Reson. Chem. 2003, 41, 721.

(22) Kyziol, J.; Broda, M.; Zaleski, J.; Daszkiewicz, Z. J. Mol. Struct. 2002, 605, 157

(23) Szemik-Hojniak, A.; Glowiak, T.; Deperasinska, I.; Puszko, A. Can. J. Chem. 2002, 80, 1242

(24) Szemik-Hojniak, A.; Glowiak, T.; Deperasinska, I.; Puszko, A. J. Mol. Struct. 2001, 597, 279.

(25) Michalski, J.; Hanuza, J.; Maczka, M.; Talik, Z.; Glowiak, T.; Szemik-Hojniak, A.; der Maas, J. H. V. J. Mol. Struct. 2001, 596, 109.

(26) Daszkiewicz, Z.; Kyziol, J. B.; Zaleski, J. J. Mol. Struct. 1999, 513,69

(27) Gawinecki, R.; Raczynska, E. D.; Rasalla, D.; Styrcz, S. Tetrahedron 1997, 53, 17211.

(28) Astakhov, A.; Vasil'ev, A.; Molokeev, M.; Revenko, V.; Stepanov, R. Russ. J. Org. Chem. 2005, 41, 910

(29) Novikova, T.; Metelkina, E.; Efimova, T.; Zaskokina, D.; Berestovitskaya, V. M. Russ. J. Org. Chem. 2005, 41, 938.

(30) Novikova, T. A.; T. P. E.; Metelkina, E. L.; Berestovitskaya, V. M. Russ. J. Org. Chem. 2004, 40, 596
(31) Bracuti, A. J. Chem. Crystallogr. 2004, 34, 135-140.

(32) Astakhov, A.; Vasil'ev, A.; Gelemurzina, I.; Sokolenko, V.; Kruglyakova, L.; Stepanov, R. Russ. J. Org. Chem. 2003, 39, 120.

(33) Cliff, M.; Dagley, I.; Parker, R.; Walker, G. Propellants, Explos., Pyrotech. 1998, 23, 179-181. 843.

(34) Moskalenko, G.; Shkurko, O. Chem. Heterocycl. Compd. 1997, 33,

(35) Daszkiewicz, Z.; Spaleniak, G.; Kyziol, J. B. J. Phys. Org. Chem. 2002, 15,115 .

(36) Koch, W.; Holthausen, M. A Chemist's Guide to Density Functional Theory, 2nd ed.; Wiley: New York, 2001.

(37) Rozenberg, M.; Jung, C.; Shoham, G. Spectrochim. Acta, Part A 2005, 61, 733.

(38) Rozenberg, M.; Shoham, G.; Reva, I.; Fausto, R. Phys. Chem. Chem. Phys. 2005, 7, 2376.

(39) Rozenberg, M.; Shoham, G.; Reva, I.; Fausto, R. Spectrochim. Acta Part A 2004, 60, 463

(40) Rozenberg, M.; Shoham, G.; Fausto, I. R. R. Spectrochim. Acta Part A 2004, 60, 2323

(41) Rozenberg, M.; Shoham, G.; Reva, I.; Fausto, R. Spectrochim. Acta Part A 2004, 60, 463 .

(42) Rozenberg, M.; Jung, C.; Shoham, G. Spectrochim. Acta, Part A 2004, 60, 2369.

(43) Rozenberg, M.; Shoham, G.; Reva, I.; Fausto, R. Spectrochim. Acta Part A 2003, 59, 3253.

(44) Adesokan, A.; Fredj, E.; Brown, E.; Gerber, R. Mol. Phys. 2005, 103,1505

(45) Barone, V. Chem. Phys. Lett. 2004, 383, 528

(46) Barone, V.; Festa, G.; Grandi, A.; Rega, N.; Sanna, N. Chem. Phys. Lett. 2004, 388, 279

(47) Frisch, M. J.; Trucks, G. W.; Schlegel, H. B.; Scuseria, G. E.; Robb M. A.; Cheeseman, J. R.; Montgomery, J. A., Jr.; Vreven, T.; Kudin, K. N.; Burant, J. C.; Millam, J. M.; Iyengar, S. S.; Tomasi, J.; Barone, V.; Mennucci, B.; Cossi, M; Scalmani, G.; Rega, N.; Petersson, G. A.; Nakatsuji, H.; Hada, M.; Ehara, M.; Toyota, K.; Fukuda, R.; Hasegawa, J.; Ishida, M.; Nakajima, T.; Honda, Y.; Kitao, O.; Nakai, H.; Klene, M.; Li, X.; Knox, J. E.; Hratchian, H. P.; Cross, J. B.; Bakken, V.; Adamo, C.; Jaramillo, J.; Gomperts, R.; Stratmann, R. E.; Yazyev, O.; Austin, A. J.; Cammi, R. Pomelli, C.; Ochterski, J. W.; Ayala, P. Y.; Morokuma, K.; Voth, G. A.; Salvador, P.; Dannenberg, J. J.; Zakrzewski, V. G.; Dapprich, S.; Daniels, A. D.; Strain, M. C.; Farkas, O.; Malick, D. K.; Rabuck, A. D.; Raghavachari, K.; Foresman, J. B.; Ortiz, J. V.; Cui, Q.; Baboul, A. G.; Clifford, S.; Cioslowski, J.; Stefanov, B. B.; Liu, G.; Liashenko, A.; Piskorz, P.; Komaromi, I.; Martin, R. L.; Fox, D. J.; Keith, T.; Al-Laham, M. A.; Peng, C. Y.; Nanayakkara, A.; Challacombe, M.; Gill, P. M. W.; Johnson, B.; Chen, W.; Wong, M. W.; Gonzalez, C.; Pople, J. A. Gaussian 03, revision D.01; Gaussian, Inc., Wallingford, CT, 2004.

(48) Parr, R.; Wang, W. Density-Functional Theory of Atoms and Molecules; Oxford University Press: New York, 1994.

(49) Neumann, R.; Nobes, R.; Handy, N. Mol. Phys. 1996, 87, 1.

(50) Møller, C.; Plesset, M. Phys. Rev. 1934, 46, 618.

(51) Becke, A. D. Phys. Rev. A 1988, 38, 3098.

(52) Lee, C.; Yang, W.; Parr, R. G. Phys. Rev. B 1988, 37, 785

(53) Becke, A. D. J. Chem. Phys. 1993, 98, 5648.

(54) Hariharan, P.; Pople, J. Chem. Phys. Lett. 1972, 66, 217

(55) Hehre, W. J.; Ditchfield, R.; Pople, J. A. J. Chem. Phys. 1972, 56

(56) Binkley, J.; Pople, J. Int. J. Quantum Chem. 1975, 9, 229.

(57) Krishnan, R.; Frisch, M.; Pople, J. J. Chem. Phys. 1980, 72, 4244

(58) Frisch, M.; Pople, J.; Binkley, J. J. Chem. Phys. 1984, 80, 3265.

(59) Dunning, T., Jr. J. Chem. Phys. 1989, 90, 1007

(60) Scalmani, G.; Barone, V.; Kudin, K.; Pomelli, C.; Scuseria, G.; Frisch, M. Theor. Chem. Acc. 2004, 111, 90

(61) Cossi, M.; Rega, N.; Scalmani, G.; Barone, V. J. Comput. Chem. 2003, 24, 669.

(62) Cossi, M.; Scalmani, G.; Rega, N.; Barone, V. J. Chem. Phys. 2002, 117,43 .

(63) Cossi, M.; Rega, N.; Scalmani, G.; Barone, V. J. Chem. Phys. 2001, 114,5691

(64) Mennucci, B.; Cances, E.; Tomasi, J. J. Phys. Chem. B 1997, 101 , 10506

(65) Mennucci, B.; Tomasi, J. J. Chem. Phys. 1996, 106, 5151.

(66) Barone, V. J. Chem. Phys. 2005, 122, 014108.

(67) Barone, V.; Manichino, C. J. Mol. Struct. 1995, 330, 365.

(68) Peng, C.; Ayala, P. Y.; Schlegel, H. B.; Frisch, M. J. J. Comput Chem. 1996, 17, 49.

(69) Breda, S.; Reva, I.; Lapinski, L.; Nowak, M.; Fausto, R. J. Mol. Struct. 2006, 786, 193 